UDK: 72.012:728.5
DOI: https://doi.org/10.24867/03FA03Ristanic

\title{
INTEGRISANI PRISTUP PROJEKTOVANJU I FABRIKACIJI ZAKRIVLJENIH FORMI U ENTERIJERU KONCERTNIH DVORANA
}

\section{INTEGRATED APPROACH FOR CURVED FORMS DESIGN AND FABRICATION OF CONCERT HALL INTERIORS}

\author{
Simo Ristanić, Fakultet tehničkih nauka, Novi Sad
}

\section{Oblast - ARHITEKTURA}

Kratak sadržaj - U ovom radu opisan je pristup projektovanju, fabrikaciji $i$ montaži enterijera koncertne dvorane, koja se sastoji od velikog broja elemenata koji sačinjavaju jednu kompleksnu formu.

Ključne reči: Projektovanje enterijera, kompleksna forma

Abstract - This paper describes process of designing, manufacturing and installation of the interior of the concert hall, which consists of a large number of elements that form a complex form together.

Keywords: Interior design, complex form

\section{UVOD}

Koncertne dvorane često u arhitektonskom i u kulturnom smislu predstavljaju simbole i identitet jednog grada. Takvo svojstvo se postiže prevashodno formom i funkcijom koncertnih dvorana. Ako se pažnja usmeri na primere iz perioda od XVIII pa do druge polovine XX veka, moguće je primetiti da se forma, odnosno oblik sale nije značajnije menjao (Beranek, 2012). Empirijski određeni proporcijski odnosi su zadržani kako bi se omogućilo neometano održavanje muzičkih događaja. Na taj način osnovna funkcija koncertnih sala je ostala nenarušena. Razvojem tehnologije građenja, kao i pojavom novih materijala, otvorila se mogućnost za istraživanje novih oblika dvorana. Na primeru projekta operske dvorane Jerna Ucona (Jorn Utzon) postalo je jasno da forma i funkcija moraju da idu kao integrisan par potreba projekta, a ne na uštrb jedna druge. Daljim razvojem digitalnih tehnika i alatki, među kojima i onih za simulaciju kretanja zvuka (Arup, Sandy Brown, 2018), postalo je moguće da se estetika forme unapredi, a da se zadrži i kvalitet zvuka i funkcionalnost.

$\mathrm{U}$ arhitekturi, odnosno $\mathrm{u}$ enterijeru uloga zakrivljenih površi je prevashodno estetska. Takvi elementi služe da omoguće drugačiji doživljaj prostora kroz svoju formu, dok se manje pažnje usmerava na funkciju takvih elemenata. Međutim kada je u pitanju enterijer koncertnih dvorana, potrebno je sagledavanje $\mathrm{i}$ forme $\mathrm{i}$ funkcije takvih elemenata, kroz integrisani pristup fabrikaciji. Integrisani pristup fabrikaciji predstavlja uključivanje više različitih oblasti u ranoj fazi projektovanja (dizajn, analiza zvuka i fabrikacija, kao najbitnije oblasti za ovo istraživanje). Predmet istraživanja ovog rada je proces fabrikovanja arhitektonskih panela kompleksne geometrije u enterijerima koncertnih dvorana.

\section{NAPOMENA:}

Ovaj rad je proistekao iz master rada čiji mentor je bio dr Bojan Tepavčević.

\section{METODE}

U ovom istraživanju je primarno korišćena metoda algoritamskog modelovanja. Primena date metode podrazumeva upotrebu $\mathrm{CAD}^{1}$ i $\mathrm{CAM}^{2}$ softvera, pomoću kojih je moguće generisati računarske modele stvarnih elemenata iz kojih se dalje mogu izvlačiti dodatne informacije. Primenom niza instrukcija, algoritama, olakšava se proces modelovanja, jer se ceo proces automatizuje, aplicirajući jednu logiku modelovanja na slične elemente. Pored metode modelovanja, primenjena je i metoda numeričkih optimizacija, prevashodno korišćena za određivanje veličine i oblika elemenata iz kojih će se fabrikovati elementi date forme.

$\mathrm{Na}$ konkretnom primeru nove filharmonijske dvorane $\mathrm{u}$ Moskvi, bilo je potrebno obložiti betonsku konstrukciju sa 19000 akustičnih panela. Glavna napomena postavljena kao projektantski kriterijum, a u cilju obezbeđivanja adekvatne akustike prostora, bila je da se obloge izvedu od drveta i da masa panela bude $120 \mathrm{~kg}$, mereno za veličinu panela od $1 \mathrm{~m}^{2}$. Na osnovu ove činjenice, a primenom metoda algoritamskog modelovanja i numeričkih optimizacija bilo je moguće pristupiti procesu integrisanog pristupa fabrikaciji povezivanjem sledećih oblasti:

- podela na manje elemente koji mogu da se fabrikuju

- priprema za proces fabrikacije

- fabrikacija

- transport i montaža

\subsection{Integrisani pristup fabrikaciji}

Najzahtevniji zadatak u ovom istraživanju se odnosi na podelu forme na manje elemente. Glavni razlog složenosti ovog zadatka je uticaj mnogo faktora koji moraju zajedno da se posmatraju, gde se javlja potreba za primenom integrisanog pristupa fabrikaciji. Podela na manje elemente predstavlja proces u kojem se određuju veličina i oblik datih elemenata, sa posebnim osvrtom na način uklapanja. Kako bi se to postiglo, potrebno je sagledati svaku od faza i videti kako uslovi svake faze utiču na veličinu i oblik elementa koji treba da se fabrikuje.

U ovoj situaciji najbolje je sagledati krajnju fazu i gledati ceo proces od nazad. Ovakav način je bolji jer se odmah rešavaju uslovi, koji moraju na kraju biti ispunjeni i koji su imperativ.

${ }^{1}$ CAD - Computer Aided Design - skraćenica koja označava primenu računara u procesu projektovanja i dizajna 
U pripremi za proces fabrikacije se kao glavno ograničenje javlja prilagođavanje postojećeg modela elementa odabranom načinu fabrikacije kao i potrebama odgovarajućih softvera za generisanje putanje glodanja. Pod odabirom načina fabrikacije se određuje kako će 3D generisan model elementa da se fabrikuje. To može uključivati glodanje celog panela na petoosnoj glodalici iz jednog većeg bloka drveta, isecanje tankih pločastih elemenata iz većih ploča iste debljine primenom troosne glodalice ili dodatno obrađivanje spojenih ploča primenom industrijskog robota. Shodno tome treba pripremiti modele za primenu u softveru koji može da generiše program za glodanje uz odgovarajuću orijentaciju 3D modelovanog elementa. Priprema takođe uključuje i proces optimizacije procesa sečenja sa ciljem smanjenja otpadnog materijala.

Nakon što se sagledaju svi ovi uslovi, moguće je pristupiti procesu podele forme $\mathrm{u}$ enterijeru koncertne dvorane. Enterijer se sastoji od mnogo celina što se može videti na slici 1, od kojih je moguće izdvojiti tri različite vrste obloga uključujući:

- zidnu oblogu (WM oznake, braon boja),

- oblogu balkona ili parapet (CS oznaka, bela boja)

- difuzore (CM oznaka, bela boja)

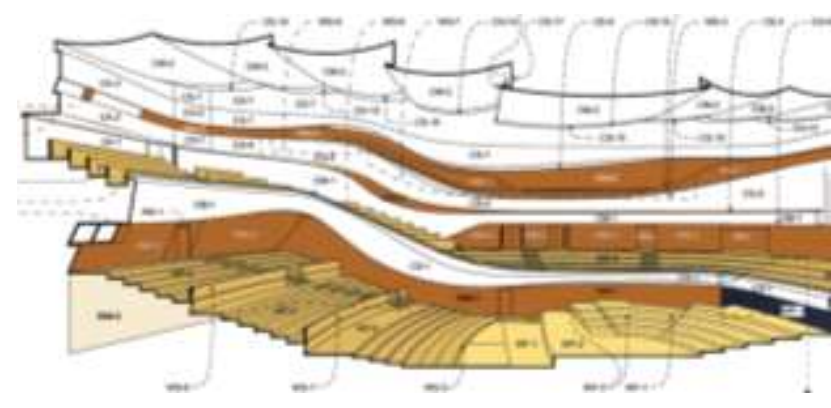

Slika 1 - poprečni presek i izgled bočne strane koncertne dvorane sa naznačenim oznaka različitih delova obloga, WM - zid, braon boja; CS - obloga balkona(parapet), bela boja; CM - difuzori, bela boja.

\subsubsection{Zidna obloga}

Kao najmanje složen deo enterijera koncertne dvorane javlja se zidna obloga. informacije o njima nalazile u 2D dokumentaciji, između ostalog u vidu razmotanog bočnog izgleda zida, izometrijskog prikaza zida Slika 2, i detalja koji pokazuju kako izgledaju ove obloge.

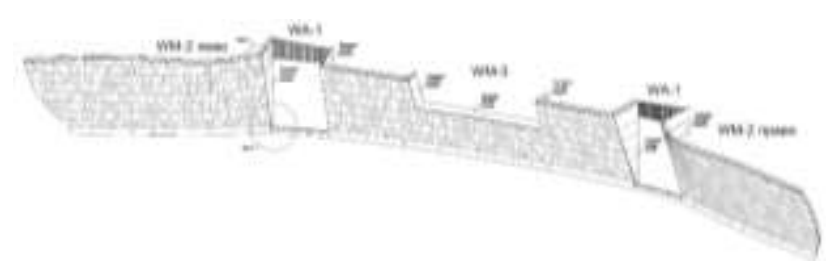

Slika 2 - izometrijski prikaz izgleda zida WM2 i WM3 sa zakrivljenim zidovima i prikazanim prizmatičnim panelima

$\mathrm{Na}$ osnovu datih informacija bilo je potrebno izmodelovati elemente i kasnije osmisliti na koji način primeniti integrisani prstup fabrikaciji. Modeli datih elemenata predstavljaju blokove određene debljine sa nepravilnom geometrijom prizmatičnih ispupčenja.

Za izvođenje ove zidne obloge, izuzetno je bilo korisno primeniti integrisani pristup fabrikaciji. Glavni razlog je dostupnost svih ograničenja različitih faza u ranoj fazi rada. Na konkretnom primeru, sagledani su 2D crteži elemenata obloge, način uklapanja i dostupni radni prostori mašina za fabrikaciju, kako bi se izmodelovao element. Kasnije je takav model podeljen na segmente tako da odgovaraju procesu fabrikacije. Primena metode optimizacije smanjuje otpadni materijal, posebno na zakrivljenim delovima zida i omogućava bolji raspored pločastih delova koji se seku iz jedne ploče.

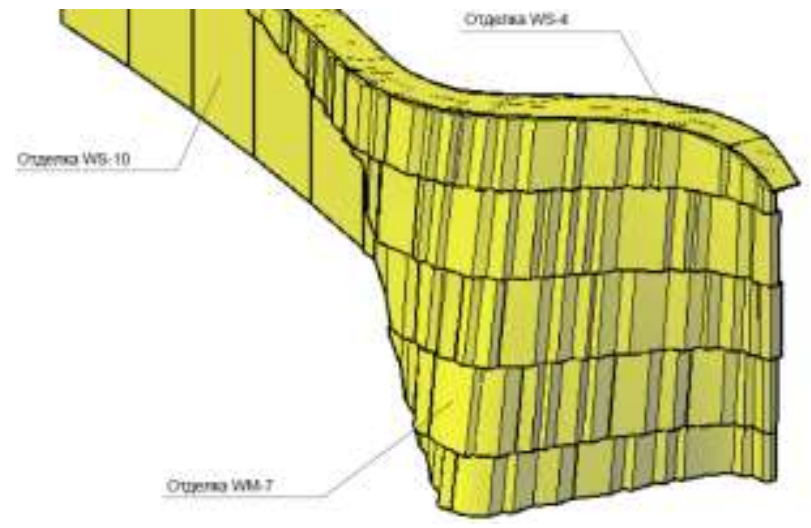

Slika 3 - 3D prikaz, zakrivljenog drvenog zida WM7

\subsubsection{Obloga balkona - parapet}

Obloga balkona predstavlja složeniju strukturu od obloge zida. Za razliku od nepravilne geometrije prizmatičnih elemenata, geometrija obloge balkona predstavlja elegantnu zakrivljenu strukturu sa kontinualnom, krivudavom i ispupčenom linijom koja se proteže kroz ceo segment (Slika 4).

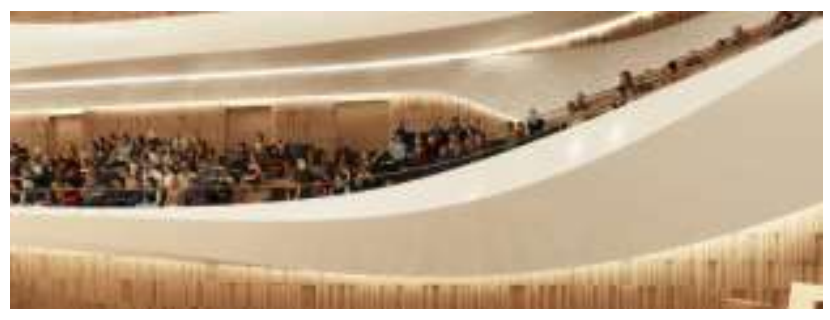

Slika 4 - render dvorane sa istaknutom ogradom balkona $u$ beloj boji i naglašenom krivudavom linijom duž celog segmenta

Uzimajući da je obloga balkona data kao jedan jedinstven 3D solid, bilo je potrebno u potpunosti osmisliti najbolji način podele. Za razliku od prethodnog slučaja gde je postojala podela i elementi su bili sitniji (red veličine $50 \mathrm{~cm} \times 70 \mathrm{~cm}$ ), u ovom slučaju je, zbog promene oblika obloge, a samim tim i veličine elemenata (red veličine $\mathrm{i}$ preko $300 \mathrm{~cm}$ ) bilo potrebno primeniti integrisani pristup fabrikaciji. 
Proces je takođe započet posmatrajući krajnju fazu montiranje. Zbog promenljivog oblika forme i promenama u visini, ovde nije bilo moguće osmisliti spojnicu za adekvatno uklapanje kao u prethodnom slučaju. Međutim veći problem je bio kako uklopiti elemente, a da se postigne kontinualna linija tj. da se izbegne nepoklapanje međusobno susednih elemenata.

Vršenje podele tako što se ceo solid seče ravnima koje su upravne na zakrivljenu površ na koju naležu je delovalo kao jednostavno rešenje. Međutim, praksa je pokazala da male nepravilnosti u betonskoj konstrukciji ili prilikom fabrikacije mogu dovesti do odstupanja.

Takođe, uzimajući ogroman prostor, postalo bi jako problematično sagledati sve delove u celini dok se ne stigne do kraja segmenta, nakon čega bi se tek uočili problemi. Kako bi se to izbeglo, podela je izvršena $u$ odnosu na postojeću ortogonalnu rastersku strukturu nosećih elemenata. To je značilo da za svaki element može da se proveri da li stoji na odgovarajućoj poziciji, nakon čega mogu da se izvrše korekcije, što drastično smanjuje utrošak vremena.

$\mathrm{Na}$ konkretnom primeru, materijal je bio MDF medijapan debljine $30 \mathrm{~mm}$, za element širine $180 \mathrm{~cm}$, to je značilo da treba da postoji 60 slepljenih ploča. Prosto lepljenje ploča bi iziskivalo previše lepka i vremena, pri čemu bi posebnu pažnju trebalo obratiti na poravnanje velikog broja ploča.

Kako bi se nadvladala takva situacija, elementi su podeljeni u četiri segmenta, gde je svaki segment imao po 15 ploča sa rupama za poravnanje.

Troosne glodalice su iskorišćene za obradu bočnih ivica ploča do te mere da su im ivice ravne, a da se u zapreminu ploče može smestiti krivudavi oblik ivica. Na taj način nije potrošeno mnogo vremena za obradu bočnih ivica, već je to ostavljeno za kasniju finalnu obradu primenom robota.

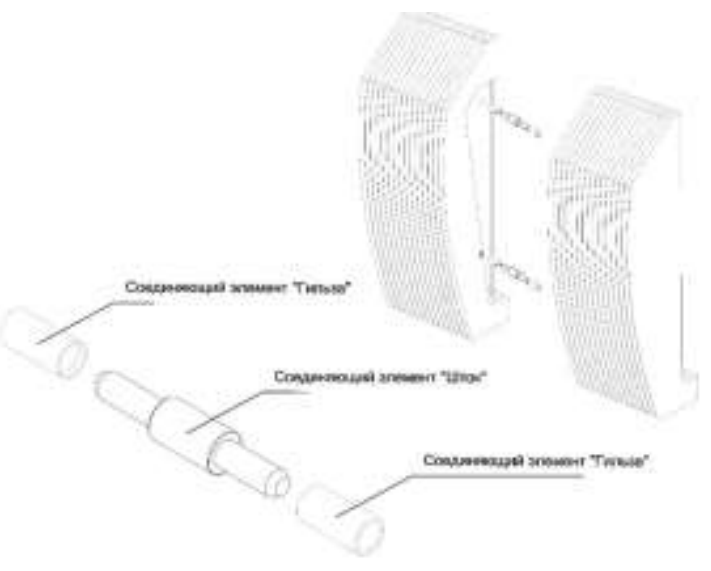

Slika 5 - prikaz spojenih krivudavih ploča u segmente koji čine jedan element obloge balkona

Tako fabrikovane elemente je onda bilo potrebno montirati na betonsku konstrukciju, za šta je bilo potrebno dodati još nekoliko rupa na bočne strane elemenata u cilju kačenja na metalnu potkonsturkciju koja će biti montirana na betonsku konstrukciju.
Velika razlika u veličini nije uslovila i različite načine transportovanja i montiranja, usled velike mase koju svaki element treba da ima.

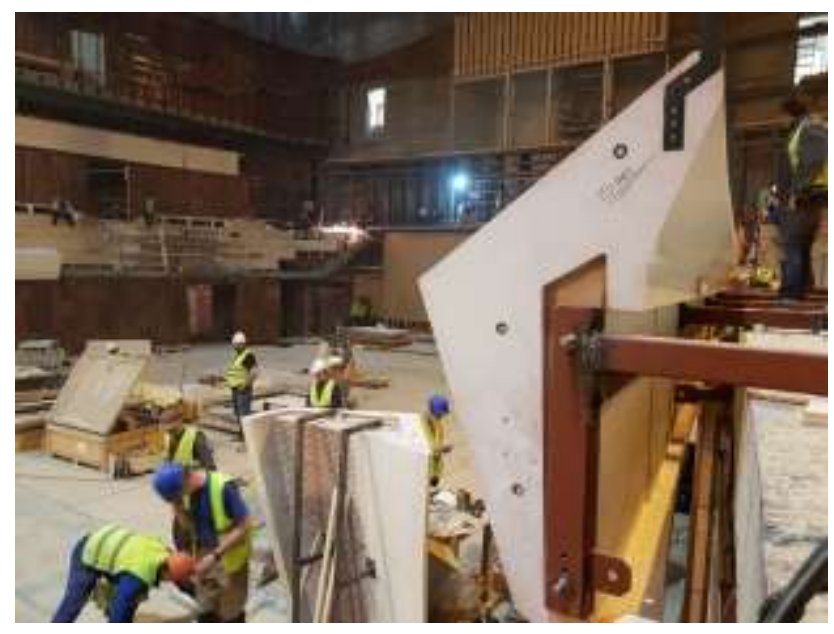

Slika 6 - prikaz vidljivih pločastih isečaka u okviru jednog elementa (levo) i montiran element sa bočnim rupama za pozicioniranje (desno)

Integrisani pristup fabrikaciji primenjen na primeru obloge balkona je bio izuzetno koristan. Prvo, sagledavanje svih faza pre montiranja omogućilo je da se izvrši adekvatna podela koja je omogućila dobro poklapanje elemenata. Primena algoritamskog načina projektovanja predstavlja dobar način da se automatizuje proces projektovanja, primenjujući niz instrukcija iterativno na različite elemente. Kombinovana primena troosne glodalice za ravnu obradu ivica krivudavih isečaka, koji se nakon spajanja obrađuju dodatno petoosnom godalicom ili glodalicom montiranoj na robota smanjuje vreme potrebno za fabrikaciju.

\subsubsection{Difuzori}

Difuzori u enterijeru koncertnih dvorana služe da rasprše zvuk, kako bi se sprečila pojava eha ili neadekvatnog vremena reverberacije. Nepravilne površi u vidu prizmatičnih elemenata zidne obloge (objašnjene $u$ potpoglavlju 2.1.1) imaju sličnu ulogu, ali različitu geometriju u odnosu na oblogu difuzora koje je trebalo uraditi (Slika 7).

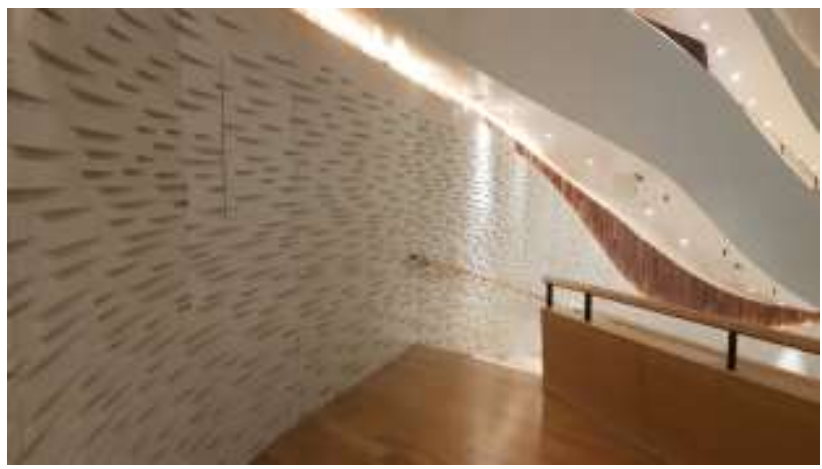

Slika 7 - Prikaz obloge difuzora sa nepravilnom geometrjom u vidu udubljenja 


\section{ZAKLJUČAK}

U ovom radu, predmet istraživanja su prednosti primene parametarskog pristupa pri projektovanju i fabrikaciji zakrviljenih elemenata u enterijeru koncertnih dvorana. U te svrhe primenjen je integrisani pristup fabrikaciji, algoritamski način modelovanja i optimizacioni algoritmi.

Zaključak je da je primena integrisanog pristupa fabrikaciji izuzetno bitna za ovakve i slične projekte. Glavni razlog toga je sagledavanje svih relevantnih oblasti i celina pre početka procesa modelovanja ili pripreme za fabrikaciju. Takvo sagledavanje je pre svega vremenski efikasno, jer uključuje sva relevantna ograničenja u ranoj fazi rada. U integrisanom pristupu fabrikaciji, najbolje je sagledati oblasti koje posmatrano po fazama dolaze na kraju, jer se takva ograničenja mogu posmatrati kao imperativ. Kada se analiziraju ograničenja svih ostalih oblasti, stvara se jasna slika o tome kakvi elementi treba da budu tj. koji elementi će zadovoljiti sva ograničenja odjednom, a ne posebno po svakoj fazi.

Kao prednost javlja se i algoritamski pristup modelovanju. Kada se jednom odredi niz instrukcija koji je potreban da bi se element izmodelovao, datu logiku je moguće aplicirati na sve ostale primere, smanjujući opet vreme potrebno za izradu i povećavajući automatizovanost celog procesa. Na taj način, repetitivne radnje se mogu odstraniti, a ako se uoči problem u takvom načinu modelovanja, prostom promenom instrukcija se proces opet ponavlja, opet štedeći na vremenu.

Uzimajući da algoritmi čine niz instrukcija, unutar svakog algoritma moguće je ubaciti i određen proces optimizacije. Optimizacioni algoritmi su posebno bitni za ovakve projekte jer smanjuju količinu otpadnog materijala, vreme procesa obrade i donose velike finansijske uštede. Optimizacioni algoritam ima zadatak da prilikom virtuelnog slaganja elemenata (zahtevane geometrijske oblike), složi na radnu ploču materijala koji se obrađuje tako da iskorištenost dovede do maksimalnog procenta.

Primenom optimizacionih algoritama moguće je odrediti minimalnu zapreminu elementa koji radne mašine u ovom slučaju petoosna glodalica ili industrijski robot trebaju da obrade kako bi dobili zahtevani trodimenzionalni element.

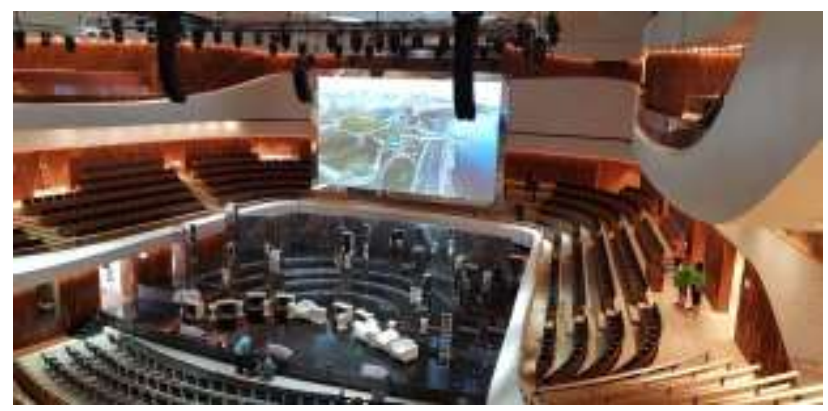

Slika 9 - Prikaz završenog enterijera koncertne dvorane u Moskvi

\section{LITERATURA}

- Arup, 2018, https://www.arup.com/contact, pristupljeno 24.9. 2018.

- Beranek, L., 2012. Concert halls and opera houses: music, acoustics, and architecture. Springer Science \& Business Media.

- Enterijer Janković, Collection 2018, http://www.enterijer-jankovic.co.rs/katalog/EJ-groupcatalogue-2018.pdf pristupljeno 27.9.2018.

- Etherington, R., 2009, JS Bach Chamber Music Hall by Zaha Hadid Architects, Dezeen, https://www.dezeen.com/2009/07/07/js-bachchamber-music-hall-by-zaha-hadid-architects/ pristupljeno 25.9.2018.

- Guangzhou Opera House / Zaha Hadid Architects, 2011, March 1, https://www.archdaily.com/115949/guangzhouopera-house-zaha-hadid-architects pristupljeno 25.9. 2018.

\section{Kratka biografija:}

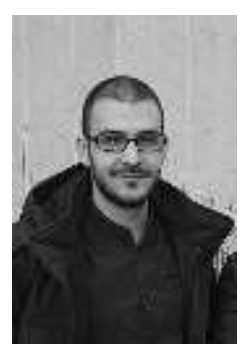

Simo Ristanić rođen je u Brčkom, Bosna i Hercegovina, 1992. godine. Osnovne studije završio u Banja Luci na Arhitektonsko građevinsko geodetskom fakultetu, smer arhitektura. Trenutno zaposlen u kompaniji "Enterijer Janković", gde je radio na projektu Moskovske filharmonije - Zaryadye concert hall. 